\title{
Study on Pile Fabrics
}

\section{Part 2: Structures of Pile Fabrics}

\author{
By Toyonori Nishimatsu* and Teiji Sawaki**, Members, TMSJ \\ *Mie Prefectural Industrial Research Institute, Tsu, Mie Pref. \\ **Chubu Institute of Technology, Kasugai, Aichi Pref.
}

Based on Journal of the Textile Machinery Society of Japan, Transactions, Vol. 35, No. 10, T146-T152 (1982-10)

\begin{abstract}
Structures and characteristics of backing layers and pile layers of pile fabrics were studied. Results obtained are as follows.

(1) Assuming that the structures of the backing layer is 3-pick terry, the basic setting value for ground warps $\left(E_{G O}\right)$ and wefts $\left(E_{S O}\right)$ may be expressed by:

$E_{G O}=E_{G}(\sqrt{G}+\sqrt{P}) / 48.6$

$E_{S O}=E_{S}(3 \sqrt{W}+2 \sqrt{P}) / 121.5$

where the basic setting value is the end density of the pile fabric woven by ground warps $1 \mathrm{~s}$, wefts $1 \mathrm{~s}$ and the pile warps $1 \mathrm{~s}$. $E_{G}$ is the warp density, $E_{S}$ the weft density. $G$ is the yarn count of ground warps, $P$ the yarn count of pile warps, and $W$ the yarn count of wefts.

(2) The pile inclination $(\theta)$ may be calculated by,

$\theta=\cos ^{-1}\left(1 / 0.33 E_{S}+d_{p} / 2\right) /\left(l_{h}+d_{p} / 2\right)$

where $E_{S}$ is the weft density, $d_{p}$ the pile diameter and $l_{h}$ the pile inclination length.

(3) Frictional and compressive properties of pile fabrics were not influenced by the fabric density of the backing layer.
\end{abstract}

\section{Introduction}

The structure of pile fabrics is divided into two layers: one is a pile layer and the other a backing layer. The former is constituted of pile yarns, and the latter of weft and warp yarns. As both sides of pile fabrics are covered with the pile layer and the middle forms the backing layer, the characteristics of pile fabrics may be determined by the pile layer.

In the previous paper ${ }^{[1]}$, the relationship between the sensory values for good feel and physical properties of pile fabrics was studied by means of the factor analysis. It was found there that the sensory values were influenced by compressive, frictional and bending properties. But there are few papers $^{[2,3]}$ on the structure of pile fabrics and the relation between the fabric structure and physical properties. So in this paper we studied the structure of pile fabrics and the relation between the backing layer and frictional and compressive properties.

\section{Structure of Pile Fabrics}

Among pile fabrics, terry fabrics are woven by a special weaving "terry motion". Figure 1 shows the cross-section of pile formation for 3-pick terry, in which two picks are first

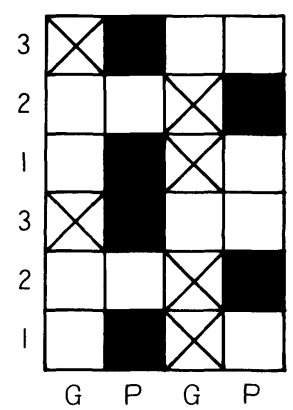

(a)

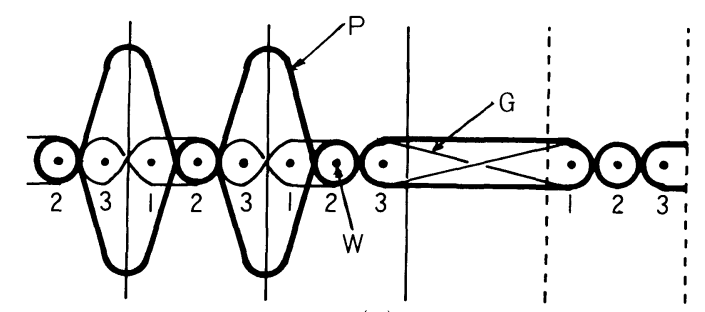

(b)
1, 2: Loose pick
3: Fast pick
$P$ : Pile warp
$G$ : Ground warp
$W$ : Weft

Fig. 1 Cross-section of pile formation for 3-pick terry. 
beaten up to a determined distance from the fabric fell. The third pick is then beaten up against the fell together with the two preceding picks. Wefts thereby slip along tensioned ground warps. The pile warp ends now form new piles.

\subsection{Pile Structure}

Pile warps are divided into single yarns and two-ply yarns. The twist direction of single yarns is different from that of two-ply yarns as shown in Figure 2. As single yarns have Ztwist, their piles are twisted in the right direction. On the other, as two-ply yarns have S-twist, their piles are twisted in the left.

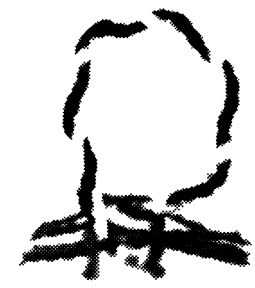

(a)

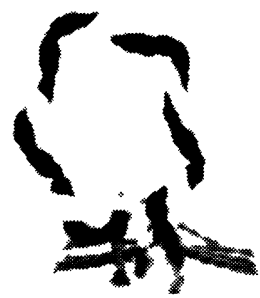

(c)

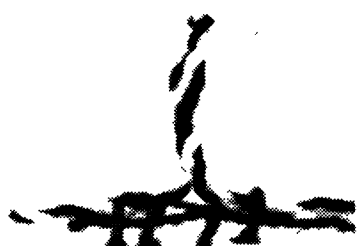

(b)

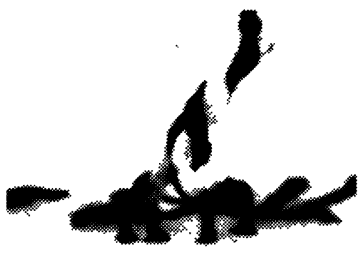

(d) (a), (b): Single yarn; (c), (d): Two-ply yarn;

(a), (c): Front view; (b), (d): Side view.

Fig. 2 Pile structure

This indicates that piles twist in the opposite direction by the untwisting effect of yarns when the third pick approaches the fabric fell. Also, as the third pick is beaten up at the bottom of pile warps, piles incline to the opposite side of the fell.

\subsection{Structure of Backing Layers}

The fabric structure of backing layers is 3-pick terry as shown in Fig. 1(a). The pile is held by the yarn to yarn friction caused among pile warps, ground warps, and wefts.

\section{Theory}

\subsection{Basic Setting Values}

Hitherto, the optimum fabric setting values have been determined empirically. Warp and weft densities depend on the number of threads per unit length, and on the yarn counts of ground warps, wefts and pile warps. So the setting value de- termined by the standard values of the fabric density and the yarn counts will be called the "basic setting value"[4].

Now, as standard values, $1 \mathrm{~s}$ will be chosen for the yarn count of ground warps, wefts and pile warps, and $1 \mathrm{end} / \mathrm{cm}$ for warp density, 3 ends/cm for weft density. Thus, the basic setting values for ground warps and wefts are defined as 1.0.

When the basic setting values are given, the warp and the weft densities can be calculated for any desired combination of counts. And these setting values are useful in developing new terry fabrics.

The basic setting values for ground warps and wefts are calculated as follows:

$$
\begin{aligned}
& E_{G 0}=E_{G}(\sqrt{G}+\sqrt{P}) / 478.6 \ldots \\
& E_{S 0}=E_{S}(3 \sqrt{W}+2 \sqrt{P}) / 121.5
\end{aligned}
$$

where

$G$ : Tex count of ground warps,

$W$ : Tex count of wefts,

$P$ : Tex count of pile warps,

$E_{G}$ : No. of ends per $\mathrm{cm}$ of ground warps,

$E_{S}$ : No. of picks per $\mathrm{cm}$.

Equation (1) is valid only with the ratio of one ground warp and one pile warp.

Various setting values of terry fabrics are shown in Figure 3. $E_{G 0}$ values vary from 2.0 to 4.0 , and $E_{S 0}$ values from 4.0 to 6.5. Higher basic setting values are assumed for wefts $\left(E_{S 0}\right)$, because the weft density is responsible for the pile fixing.

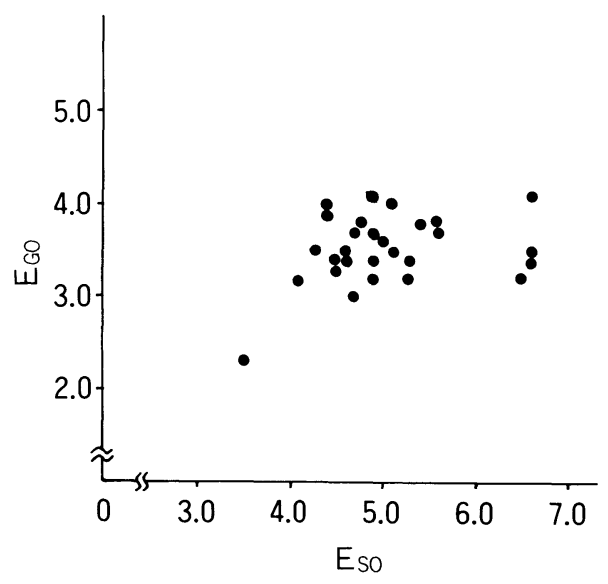

Fig. 3 Basic setting values of ground warps $\left(E_{G O}\right)$ and wefts $\left(E_{S O}\right)$ for various pile fabrics.

Figure 4 shows the upper (4.0) and lower (2.0) values of the basic warp setting for various yarn counts of ground and pile warps in ends/cm. For example, when $E_{G 0}$ is 2.0 and the yarn counts of ground and pile warps are $10 \mathrm{~s}, E_{G}$ becomes 6.3 ends/cm from Fig. 4.

On the other hand, Figure 5 shows the upper (6.5) and lower (4.0) values of the basic weft setting for various yarn counts of wefts and pile warps in ends $/ \mathrm{cm}$. 


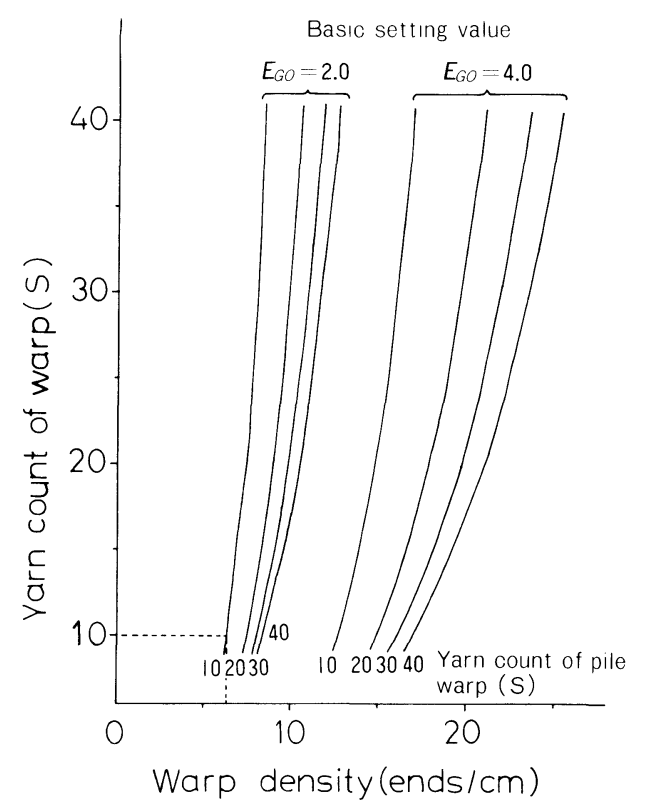

Fig. 4 Maximum and minimum basic setting values for warps.

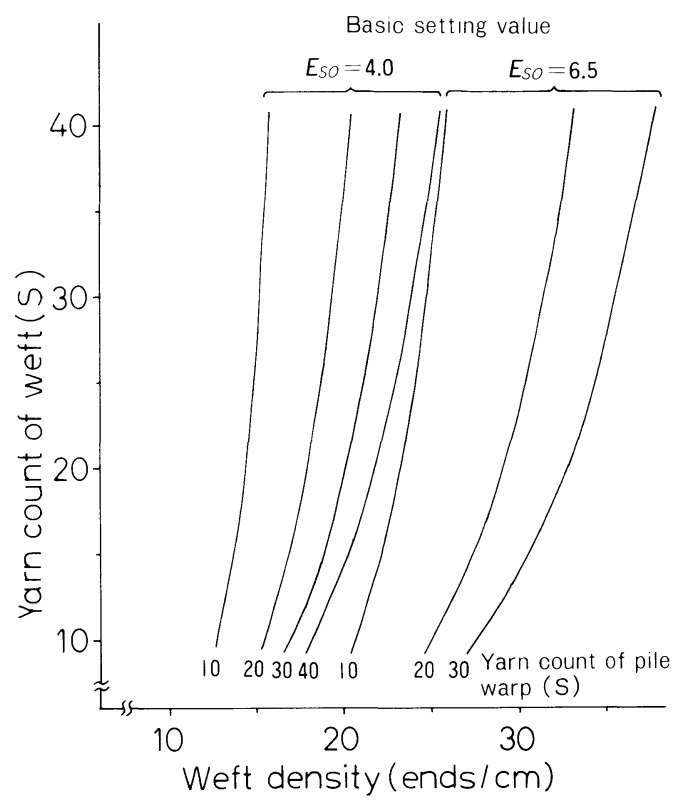

Fig. 5 Maximum and minimum basic setting values for wefts.

\subsection{Pile Inclination}

The pile inclines to the opposite side of the fell as shown in Fig. 2, (b) and (d). Figure 6 shows the side view of a pile model. It is assumed that point $\mathrm{A}$ is on the perpendicular line to the warp axis, and touches the first weft yarn in Fig. 6. Numbers 1, 2 and 3 in Fig. 6 show the first, the second and

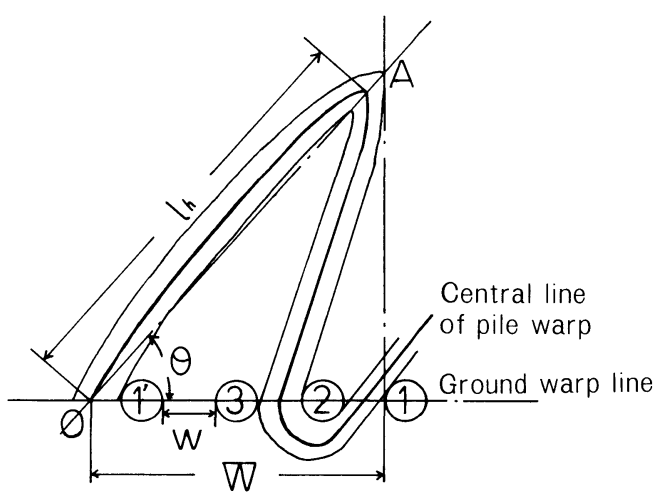

Fig. 6 Side view of pile model.

the third weft yarns. If

$R_{p}$ : Pile ratio,

$d$ : Weft yarn diameter $(\mathrm{cm})$,

$d_{p}$ : Pile warp diameter $(\mathrm{cm})$,

$l$ : Unit per length $(=1 \mathrm{~cm})$,

$E_{S}$ : Weft density (ends/cm),

$m$ : Numbers of piles per $1 \mathrm{~cm}$ warp distance (numbers/ $\mathrm{cm}$ ),

$l_{p}:$ Pile length $(\mathrm{cm})$,

$w$ : Distance from the first weft to the third weft $(\mathrm{cm})$, then, the definition of the pile ratio $R_{p}$,

$$
R_{p}=\left(l_{p}+\left(d+d_{p}\right) / 2\right) \times m / l .
$$

Now as $l$ is $1 \mathrm{~cm}$, eq. (3) becomes

$$
l_{p}=R_{p} / m-\left(d+d_{p}\right) \pi / 2
$$

From Fig. 6, $w$ is

$$
\begin{aligned}
& w=1 / m-\left(3 d+2 d_{p}\right) \\
& W=w+3 d+(5 / 2) d_{p}=1 / m+1 / 2 d_{p} \\
& =1 / 0.33 E_{s}+1 / 2 d_{p}
\end{aligned}
$$

As the pile form resembles closely an Elastic Model, we apply Leaf's Elastica Model ${ }^{[5,6]}$, and the pile length $l_{p}$ becomes

$$
l_{p}=2 n F(k, \pi / 2)
$$

where $k=\sin (\alpha / 2)$, and $\alpha$ is a measured value. So, the pile inclination length $l_{h}$ becomes

$$
l_{h}=2 n k
$$

By substituting eqs. (3)' and (6) into eq. (7), we obtain

$$
l_{h}=\left(R_{p} / m-\left(d+d_{p}\right) \pi / 2\right) k / F(k, \pi / 2)
$$

Thus, the length $\overline{O A}$ becomes

$$
l_{h}^{\prime}=l_{h}+1 / 2 d_{p}
$$

Therefore, the pile inclination $\theta$ is given by

$$
\theta=\cos ^{-1}\left(W / l_{h}{ }^{\prime}\right)
$$

\section{Experimental}

Table 1 shows samples used to measure the pile inclina- 
Table 1 Samples

\begin{tabular}{|c|c|c|c|c|c|c|c|c|}
\hline & & \multicolumn{7}{|c|}{ Sample } \\
\hline & & $A_{1}$ & $A_{2}$ & $A_{3}$ & $A_{4}$ & $A_{5}$ & $A_{6}$ & $A_{7}$ \\
\hline Yarn & Ground warp & $38.8 / 2$ & $39.2 / 2$ & $42.6 / 2$ & 17.8 & $31.8 / 2$ & $44.2 / 2$ & 20.8 \\
\hline count & Weft & 22.1 & 21.6 & 31.6 & 23.1 & 18.3 & 16.9 & 20.2 \\
\hline (s) & Pile warp & $29.8 / 2$ & $32.8 / 2$ & $41.8 / 2$ & $31.8 / 2$ & $31.4 / 2$ & 20.9 & 17.3 \\
\hline \multirow[t]{3}{*}{$\begin{array}{l}\text { Fabric } \\
\text { density }\end{array}$} & $\begin{array}{l}\text { Warp density } \\
\text { (ends/cm) }\end{array}$ & 15.7 & 14.6 & 18.1 & 13.4 & 12.6 & 15.0 & 23.6 \\
\hline & $\begin{array}{l}\text { Weft density } \\
\text { (ends/cm) }\end{array}$ & 20.9 & 20.1 & 22.8 & 20.1 & 20.5 & 17.7 & 18.9 \\
\hline & Pile ratio & 4.8 & 5.1 & 5.0 & 7.4 & 5.2 & 6.9 & 6.7 \\
\hline
\end{tabular}

tion, which was measured on the cross-sectional photographs of pile fabrics by a protractor.

The relation between the backing layer and the frictional and compressive properties was studied by using samples $A_{8}, A_{9}, A_{10}$ and $A_{11}$ shown in Table 2. Figure 7 shows the schema of the frictional measuring apparatus.

Sample was fixed on the horizontal plate and the frictional force was measured by the tension pick up when the slider was moved on the sample.

The size of the slider is $20 \times 40 \mathrm{~mm}^{2}$, the load is $17.0 \mathrm{gf}$, the moved distance of the slider is $100 \mathrm{~mm}$, the moving speed of

Table 2 Samples

\begin{tabular}{|c|c|c|c|c|c|}
\hline \multicolumn{6}{|c|}{ Sample } \\
\hline & & $A_{8}$ & $A_{9}$ & $A_{10}$ & $A_{11}$ \\
\hline Yarn & Ground warp & $40 / 2$ & $30 / 2$ & $40 / 2$ & $40 / 2$ \\
\hline count & Weft & 20 & 20 & 20 & 20 \\
\hline (s) & Pile warp & $20 / 2$ & $20 / 2$ & 20 & 20 \\
\hline \multirow[t]{3}{*}{$\begin{array}{l}\text { Fabric } \\
\text { density }\end{array}$} & $\begin{array}{l}\text { Warp density } \\
\text { (ends/cm) }\end{array}$ & 32 & 30 & 31 & 31 \\
\hline & $\begin{array}{l}\text { Weft density } \\
\text { (ends/cm) }\end{array}$ & 50 & 50 & 45 & 50 \\
\hline & Pile ratio & 4.0 & 4.0 & 4.0 & 4.0 \\
\hline
\end{tabular}

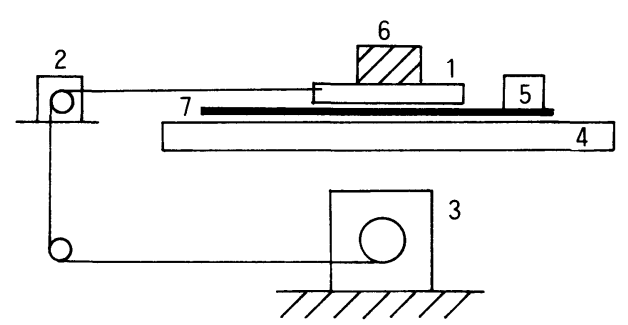

1: Slider

2: Tension Pick Up

3: Winding Apparatus

4: Horizontal Plate

5: Clamp

6: Weight

7: Sample

Fig. 7 Schema of frictional measuring apparatus. the slider is $5 \mathrm{~mm} / \mathrm{s}$. The atmosphere of the laboratory is $20^{\circ} \mathrm{C}$ and $65 \% \mathrm{RH}$.

The compressive property was measured by a compressive testing machine. The maximum pressure is $10 \mathrm{gf} / \mathrm{cm}^{2}$, the size of the compressive plate is $40 \times 40 \mathrm{~mm}^{2}$, and the compressing speed is $5 \mathrm{~mm} / \mathrm{min}$.

From the measured Pressure-Thickness curves, such values were calculated as compressive ratio $\left(R_{a}\right)$, compressive energy $\left(E_{c}\right)$, recovery energy $\left(E_{c}{ }^{\prime}\right)$, compressive resilience $\left(R_{c}\right)$, compressive modulus $\left(D_{c}\right)$ and compressive recovery ratio $\left(K_{c}\right)$.

\section{Results and Discussion}

Table 3 shows the comparison between measured values of pile inclination and calculated values by eq. (10).

Table 3 Inclination of pile, $(\theta)$

$\theta$

Sample Calculated value Experimental value $\left({ }^{\circ}\right)$

( ) Mean S.D.*

$52.9 \quad 58.9 \quad 4.5$

$\begin{array}{lll}56.2 & 59.0 & 3.9\end{array}$

$\begin{array}{lll}55.0 & 59.2 & 3.5\end{array}$

$\begin{array}{lll}67.7 & 61.8 & 4.7\end{array}$

$\begin{array}{lll}57.2 & 56.0 & 3.1\end{array}$

$66.4 \quad 61.6 \quad 4.1$

$\begin{array}{lll}64.1 & 40.0 & 3.5\end{array}$

*S.D. is Standard Deviation.

From Table 3, it is found that both calculated and measured value agree well except sample $A_{7}$. But the difference for sample $A_{7}$ is large. This may be because the twist number of its pile warps is large and piles are twisted over and over again by the untwisting torque and are inclined.

Table 4 shows the measured frictional coefficients in the warp and weft directions for samples $A_{8}, A_{9}, A_{10}$ and $A_{11}$. Table 5 shows the analysis of variance to test the effect of the warp density between $A_{8}$ and $A_{9}$, and that of the weft density between $A_{10}$ and $A_{11}$. As $F_{0.05}(1,16)$ is 4.494 and 
Table 4 Frictional coefficients of samples.

\begin{tabular}{|c|c|c|}
\hline \multicolumn{3}{|c|}{ Frictional coefficient } \\
\hline Sample & $\begin{array}{l}\text { Warp } \\
\text { direction }\end{array}$ & $\begin{array}{l}\text { Weft } \\
\text { direction }\end{array}$ \\
\hline$A_{8}$ & 0.4167 & 0.4062 \\
\hline$A_{9}$ & 0.4091 & 0.3929 \\
\hline$A_{10}$ & 0.4006 & 0.4354 \\
\hline$A_{11}$ & 0.4099 & 0.4216 \\
\hline
\end{tabular}

Table $5 \quad F_{0}$ values between samples $A_{8}$ and $A_{9}$, and samples $A_{10}$ and $A_{11}$.

$\begin{array}{lll} & F_{0}\left(A_{8}, A_{9}\right) & F_{0}\left(A_{10}, A_{11}\right) \\ \begin{array}{lll}\text { Frictional coefficient } \\ \text { in warp direction }\end{array} & 4.13 & 3.39 \\ \begin{array}{l}\text { Frictional coefficient } \\ \text { in weft direction }\end{array} & 0.62 & 0.23\end{array}$

\section{Conclusion}

Structures and characteristics of the backing layer and the pile layer of pile fabrics, and the relation between the backing layer and frictional and compressive properties were studied in this paper. The results obtained are as follows.

(1) Assuming that the structure of the backing layer is 3-pick terry, the basic setting value for ground warps $\left(E_{G 0}\right)$ and wefts $\left(E_{S 0}\right)$ may be expressed by

$$
\begin{aligned}
& E_{G 0}=E_{G}(\sqrt{G}+\sqrt{P}) / 48.6 \\
& E_{S 0}=E_{S}(3 \sqrt{W}+2 \sqrt{P}) / 121.5
\end{aligned}
$$

(2) The pile inclination $(\theta)$ may be calculated by

$$
\theta=\cos \left(1 / 0.33 E_{s}+d_{p} / 2\right) /\left(l_{h}+d_{p} / 2\right)
$$

(3) Frictional and compressive properties were not influenced by the fabric density of the backing layer.

This study was reported at the 11 th Textile Technology

Table 6 Compressive properties.

\begin{tabular}{lclllll}
\hline \multicolumn{7}{c}{ Physical properties } \\
\hline Sample & $E_{c}(\mathrm{gf} \cdot \mathrm{cm})$ & $E_{c}{ }^{\prime}(\mathrm{gf} \cdot \mathrm{cm})$ & $R_{c}(\%)$ & $R_{a}(\%)$ & $D_{c}(\%)$ & $K_{c}(\%)$ \\
\hline$A_{8}$ & 7.67 & 3.71 & 44.55 & 23.78 & 80.82 & 95.44 \\
$A_{9}$ & 8.70 & 3.95 & 45.21 & 27.47 & 77.67 & 93.87 \\
$A_{10}$ & 11.09 & 5.05 & 45.47 & 39.74 & 80.11 & 92.09 \\
$A_{11}$ & 9.42 & 4.17 & 44.23 & 34.19 & 81.74 & 93.76 \\
\hline
\end{tabular}

$F_{0.01}(1,16)$ is $8.531, F_{0}$ values are not significant at the 0.05 level.

So, the backing layer which forms the middle layer of the pile fabric doesn't influence on the frictional force, if the yarn count of pile warps, the pile ratio and numbers of the pile unit per area were identical, because the slider rubs only the surface of the pile layer.

Table 6 shows the measured compressive properties. Table 7 shows the analysis of variance to test the effect of the warp density between $A_{8}$ and $A_{9}$, and that of the weft denstity between $A_{10}$ and $A_{11}$. As $F_{0.05}(1,6)$ is 5.99 and $F_{0.01}(1,6)$ is 13.74, compressive energy, recovery energy, compressive resilience, compressive modulus and compressive recovery ratio are not significant, and compressive ratio is significant at the 0.01 level.

It was found that compressive properties (energy, compressive resilience, compressive modulus and compressive recovery ratio) were not influenced by the fabric density of the backing layer, if the yarn count of pile warps, the pile ratio and numbers of piles per unit area were identical. This is because that only the pile layer is compressed and the backing layer is not compressed.

So, we should notice the pile layer that forms the surface layer of pile fabrics when we investigate the frictional and compressive properties of pile fabrics.
Table $7 \quad F_{0}$ values between samples $A_{8}$ and $A_{9}$, and between $A_{10}$ and $\mathrm{A}_{11}$.

\begin{tabular}{lll} 
& $F_{0}\left(A_{8}, A_{9}\right)$ & $F_{0}\left(A_{10}, A_{11}\right)$ \\
\hline$E_{c}$ & 5.52 & 4.07 \\
$E_{c}$ & 3.94 & 2.92 \\
$R_{c}$ & 0.17 & 0.79 \\
$R_{a}$ & $14.18^{* *}$ & $22.39^{* *}$ \\
$D_{c}$ & 1.14 & 0.97 \\
$K_{c}$ & 3.17 & 5.52
\end{tabular}

Forum of the Textile Machinery Society of Japan (August 12, 1982).

\section{References}

[1] Nishimatsu and Sawaki; J. Text. Mach. Soc., Japan, 35, T146 (1982).

[2] Nishimatsu; Bull. of Mie Pref. Ind. Res. Inst., 3, p. 48 (1978).

[3] Nishimatsu; The 32nd Ann. Meet. Rept. of Text. Mach. Soc., Japan.

[4] M. Kienbaum; Int. Text. Bull., p. 9 (1977).

[5] Leaf; J. Text. Inst., 51, T49 (1960).

[6] Fundamental Textile Technology (III); Text. Mach. Soc., Japan. 